\title{
Article \\ Chloropentaphenyldisiloxane-Model Study on Intermolecular Interactions in the Crystal Structure of a Monofunctionalized Disiloxane ${ }^{\dagger}$
}

\author{
Jonathan O. Bauer *(D) and Tobias Götz \\ Institut für Anorganische Chemie, Fakultät für Chemie und Pharmazie, Universität Regensburg, \\ Universitätsstraße 31, D-93053 Regensburg, Germany; Tobias.Goetz@chemie.uni-regensburg.de \\ * Correspondence: Jonathan.Bauer@chemie.uni-regensburg.de \\ + Dedicated to Dr. Howard Flack (1943-2017).
}

Citation: Bauer, J.O.; Götz, T. ChloropentaphenyldisiloxaneModel Study on Intermolecular Interactions in the Crystal Structure of a Monofunctionalized Disiloxane . Chemistry 2021, 3, 444-453. https:// doi.org/10.3390/chemistry3020033

Academic Editor:

Catherine Housecroft

Received: 14 March 2021

Accepted: 25 March 2021

Published: 29 March 2021

Publisher's Note: MDPI stays neutral with regard to jurisdictional claims in published maps and institutional affiliations.

Copyright: (c) 2021 by the authors. Licensee MDPI, Basel, Switzerland. This article is an open access article distributed under the terms and conditions of the Creative Commons Attribution (CC BY) license (https:// creativecommons.org/licenses/by/ $4.0 /)$.

\begin{abstract}
Small functional siloxane units have gained great interest as molecular model systems for mimicking more complex silicate structures both in nature and in materials chemistry. The crystal structure of chloropentaphenyldisiloxane, which was synthesized for the first time, was elucidated by single-crystal X-ray diffraction analysis. The molecular crystal packing was studied in detail using state-of-the-art Hirshfeld surface analysis together with a two-dimensional fingerprint mapping of the intermolecular interactions. It was found that the phenyl $\mathrm{C}-\mathrm{H}$ bonds act as donors for both weak $\mathrm{C}-\mathrm{H} \cdots \pi$ and $\mathrm{C}-\mathrm{H} \cdots \mathrm{Cl}$ hydrogen bond interactions. The influence of intramolecular $\mathrm{Si}-\mathrm{O}-\mathrm{Si}$ bond parameters on the acceptor capability of functional groups in intermolecular hydrogen bond interactions is discussed.
\end{abstract}

Keywords: disiloxanes; intermolecular interactions; Hirshfeld surface analysis; molecular models; silicon; X-ray crystallography

\section{Introduction}

Siloxanes are known to be quite resistant towards thermal and chemical decomposition [1]. Their structural motif, the $\mathrm{Si}-\mathrm{O}-\mathrm{Si}$ bond, therefore, not only forms the basis for silicate minerals in nature, which are built from both geological [2] and biosilicification processes [3], but also the backbone for technologically important organic-inorganic hybrid polymers (silicones) [4] and for new synthetic silicate materials [5,6]. Studies on small and defined molecular siloxane models can provide very useful information on structure and reactivity of more complex siloxane-based materials and surfaces [7-17]. Silica-based biomimetic model systems [18] have also gained much interest in order to understand natural coral shapes [19] and shell formation of unicellular organisms such as diatoms [20]. We recently reported on monofunctionalized disiloxane units that served as simplified molecular model systems for investigating the reactivity and chemoselectivity in targeted further transformations [15].

The identification of weak intermolecular interactions in molecular crystals is an interesting undertaking with the aim of gaining knowledge about structure-forming forces and making it usable for the targeted formation of functional crystalline networks [21,22]. Siloxanes are of particular interest, since a large number of three-dimensional architectures can be formed through $\mathrm{Si}-\mathrm{O}$ bond formation [23]. The assembly of several siloxane units to form complex framework structures therefore requires a more detailed study of intermolecular interactions.

As part of our studies on weak intermolecular interactions in molecular crystals [24-26], we were now interested in taking a closer look at monofunctionalized disiloxanes with regard to their crystal packing and intermolecular contacts. Disiloxanes as the smallest units of oligo- and polysiloxanes are a fascinating class of substances, ideal for model studies [27]. Unymmetrically substituted crystalline disiloxanes with only one heterofunction 
are extremely rare [15,28-33], but they shed light on the influence of single substituents on the Si-O-Si unit [15]. Chlorosilanes in general are important precursors for the synthesis of other functional silanes [34] and used as silylation reagents for surface modifications [35]. We therefore chose a chlorodisiloxane (2) as an appropriate model system, which is only equipped with aryl groups as additional substituents in order to examine the role of $\mathrm{C}-\mathrm{H} \cdots \pi$ and $\mathrm{C}-\mathrm{H} \cdots \mathrm{Cl}-\mathrm{Si}$ interactions in the crystalline state more closely by using stateof-the-art analytical methods, Hirshfeld surface analysis [36] along with two-dimensional (2D) fingerprint plots [37]. As already successfully applied in previous work [15,38-40], we took advantage of the good crystallization properties that result when compounds are equipped with triphenylsiloxy groups.

\section{Experimental Details}

\subsection{General Remarks}

All experiments were performed under an inert atmosphere of purified nitrogen by using standard Schlenk techniques. Glassware was heated at $140{ }^{\circ} \mathrm{C}$ prior to use. Dichloromethane, pentane, tetrahydrofuran, and toluene were dried and degassed with an MBraun SP800 solvent purification system. $n$-Butyllithium (2.5 M solution in hexane, Merck KGaA, Darmstadt, Germany), dichlorodiphenylsilane (98\%, Merck KGaA, Darmstadt, Germany), and triphenylsilanol (98\%, Merck KGaA, Darmstadt, Germany) were used without further purification. [D6]-Benzene used for NMR spectroscopy was dried over $\mathrm{Na} / \mathrm{K}$ amalgam. NMR spectra were recorded on a Bruker Avance $300(300.13 \mathrm{MHz}$, Bruker Corporation, Billerica, MA, USA) and a Bruker Avance III HD 400 (400.13 MHz) spectrometer at $25{ }^{\circ} \mathrm{C}$. Chemical shifts $(\delta)$ are reported in parts per million $(\mathrm{ppm}) .{ }^{1} \mathrm{H}$ and ${ }^{13} \mathrm{C}\left\{{ }^{1} \mathrm{H}\right\}$ NMR spectra are referenced to tetramethylsilane ( $\mathrm{SiMe}_{4}, \delta=0.0 \mathrm{ppm}$ ) as external standard, with the deuterium signal of the solvent serving as internal lock and the residual solvent signal as an additional reference. The ${ }^{29} \mathrm{Si}$ NMR spectrum is referenced to $\mathrm{SiMe}_{4}(\delta=0.0 \mathrm{ppm})$ as the external standard. For the assignment of the multiplicities, the following abbreviations were used: $\mathrm{s}=$ singlet, $\mathrm{m}=$ multiplet. High resolution mass spectrometry was carried out on a Jeol AccuTOF GCX spectrometer. Elemental analysis was performed on a Vario MICRO cube apparatus. The IR spectrum was recorded on a Bruker ALPHA FT-IR spectrometer equipped with a diamond ATR unit. For the intensities of the bands, the following abbreviations were used: $\mathrm{s}=$ strong, $\mathrm{m}=$ medium, $\mathrm{w}=$ weak.

\subsection{Synthesis of $\mathrm{Ph}_{2} \mathrm{SiCl}\left(\mathrm{OSiPh}_{3}\right)$ (2)}

$n$-Butyllithium (22.0 mL of a $2.5 \mathrm{M}$ solution in hexane, $55.0 \mathrm{mmol}, 1.1$ equiv.) was added dropwise to a solution of triphenylsilanol (13.82 g, $50.0 \mathrm{mmol}, 1.0$ equiv.) in tetrahydrofuran $(200 \mathrm{~mL})$ at $0{ }^{\circ} \mathrm{C}$. The clear colorless solution was then allowed to slowly warm to room temperature and stirred for $1 \mathrm{~h}$. Then, the reaction mixture was again cooled to $0^{\circ} \mathrm{C}$, dichlorodiphenylsilane (1) $(10.5 \mathrm{~mL}, 50.0 \mathrm{mmol}, 1.0$ equiv.) was added and the mixture was allowed to warm to room temperature. The reaction mixture was refluxed for $5 \mathrm{~h}$. After cooling down to room temperature, all volatiles were removed in vacuo and the product was extracted in dichloromethane $(100 \mathrm{~mL})$. Again, all volatiles were removed in vacuo and the crude solid material was recrystallized from hot toluene $(30 \mathrm{~mL})$. The crystals were isolated via filtration and washed with pentane to obtain compound 2 as a white crystalline solid (15.09 g, $30.6 \mathrm{mmol}, 61 \%) .{ }^{1} \mathrm{H}$ NMR (400.13 MHz, $\left.\mathrm{C}_{6} \mathrm{D}_{6}\right): \delta=7.00-7.15\left(\mathrm{~m}, 15 \mathrm{H}, H_{P h}\right)$, 7.71-7.79 (m, 10H, $\left.H_{P h}\right) .{ }^{13} \mathrm{C}\left\{{ }^{1} \mathrm{H}\right\} \operatorname{NMR}\left(75.44 \mathrm{MHz}, \mathrm{C}_{6} \mathrm{D}_{6}\right): \delta=128.3\left(\mathrm{~s}, C_{P h}\right), 130.5\left(\mathrm{~s}, C_{P h}\right)$, $131.1\left(\mathrm{~s}, C_{P h}\right), 134.2\left(\mathrm{~s}, C_{P h}\right), 134.7\left(\mathrm{~s}, C_{P h}\right), 135.0\left(\mathrm{~s}, C_{P h}\right), 135.7\left(\mathrm{~s}, C_{P h}\right) .{ }^{29} \mathrm{Si} \mathrm{NMR}(79.49$ $\left.\mathrm{MHz}, \mathrm{C}_{6} \mathrm{D}_{6}\right): \delta=-19.6\left(\mathrm{~m}, \mathrm{SiClPh}_{2}\right),-15.7\left(\mathrm{~m}, \mathrm{SiPh}_{3}\right)$. HRMS (EI+): $\mathrm{C}_{30} \mathrm{H}_{25} \mathrm{ClOSi}_{2}$ calcd. $m / z$ for $\left[\mathrm{M}^{+}\right]$492.1127; found 492.1119. CHN analysis: $\mathrm{C}_{30} \mathrm{H}_{25} \mathrm{ClOSi}_{2}$ calcd. C 73.07\%, H 5.11\%; found C 73.11\%, H 4.97\%. FT-IR (cm $\left.{ }^{-1}\right)$ : $3070(w), 3024(w), 1590(w), 1486(w)$, 1427 (m), 1116 (s, Si-O-Si), 1096 (s), 1026 (m), 997 (m), 711 (s), 696 (s), 540 (s), 507 (s), 491 (s), 475 (s). 


\subsection{X-Ray Crystallography}

Single-crystal X-ray diffraction analysis of chloropentaphenyldisiloxane (2) was performed on a GV50 diffractometer equipped with a TitanS2 CCD detector at 123(2) K using graphite-monochromated $\mathrm{Cu}-\mathrm{K} \beta$ radiation $(\lambda=1.39222 \AA)$. Data collection and reduction was performed using the CrysAlisPro software system, version 1.171.40.14a [41]. The crystal structure was solved with SHELXT 2018/2 [42,43] and a full-matrix least-squares refinement based on $F^{2}$ was carried out with SHELXL-2018/3 [43-45] using Olex2 [46] and the SHELX program package as implemented in WinGX [47]. A multi-scan absorption correction using spherical harmonics as implemented in SCALE3 ABSPACK was employed [41]. The non-hydrogen atoms were refined using anisotropic displacement parameters. The hydrogen atoms were located on the difference Fourier map and refined independently. The Hirshfeld surface was mapped over $d_{\text {norm }}$ ranging from -0.0425 to 1.3719 a.u. $d_{\mathrm{i}}$ and $d_{\mathrm{e}}$ in the $2 \mathrm{D}$ fingerprint diagrams are the distances from the surface to the nearest atom interior and exterior to the surface, respectively, and are each given in the range of 0.4 to $3.0 \AA$. Details on crystal data and structure refinement are summarized in Table 1 (see also Supplementary Materials). The Hirshfeld surface and 2D fingerprint plots including Figures 1-3 and Appendix A Figure A1 were created using CrystalExplorer 17.5 [48].

Table 1. Crystal data and structure refinement of chloropentaphenyldisiloxane (2).

\begin{tabular}{|c|c|}
\hline Empirical formula & $\mathrm{C}_{30} \mathrm{H}_{25} \mathrm{ClOSi}_{2}$ \\
\hline Formula weight $\left[\mathrm{g} \cdot \mathrm{mol}^{-1}\right]$ & 493.13 \\
\hline Crystal system & Monoclinic \\
\hline Space group & $P 2_{1} / n$ \\
\hline$a[\AA]$ & $10.6741(2)$ \\
\hline$b[\AA]$ & $14.2858(2)$ \\
\hline$c[\AA]$ & $17.5012(3)$ \\
\hline$\alpha\left[^{\circ}\right]$ & 90 \\
\hline$\beta\left[^{\circ}\right]$ & $99.597(2)$ \\
\hline$\gamma\left[{ }^{\circ}\right]$ & 90 \\
\hline Volume $\left[\AA^{3}\right]$ & 2631.37(8) \\
\hline$Z$ & 4 \\
\hline Density (calculated) $\rho\left[\mathrm{g} \cdot \mathrm{cm}^{-3}\right]$ & 1.245 \\
\hline Absorption coefficient $\mu\left[\mathrm{mm}^{-1}\right]$ & 1.690 \\
\hline$F(000)$ & 1032 \\
\hline Crystal size $\left[\mathrm{mm}^{3}\right]$ & $0.161 \times 0.100 \times 0.084$ \\
\hline Theta range for data collection $\theta\left[{ }^{\circ}\right]$ & $3.627-69.661$ \\
\hline \multirow[t]{3}{*}{ Index ranges } & $-12 \leq h \leq 14$ \\
\hline & $-18 \leq k \leq 19$ \\
\hline & $-22 \leq l \leq 23$ \\
\hline Reflections collected & $2 \overline{2} 059$ \\
\hline Independent reflections & $6570\left(R_{\mathrm{int}}=0.0209\right)$ \\
\hline Completeness to $\theta=56.650^{\circ}$ & $99.9 \%$ \\
\hline Max. and min. transmission & 1.000 and 0.795 \\
\hline Data/restraints/parameters & $6570 / 0 / 407$ \\
\hline Goodness-of-fit on $\mathrm{F}^{2}$ & 1.045 \\
\hline Final $R$ indices $[I>2 \sigma(I)]$ & $R 1=0.0347, \mathrm{w} R 2=0.0954$ \\
\hline$R$ indices (all data) & $R 1=0.0397, \mathrm{w} R 2=0.0994$ \\
\hline Largest diff. peak and hole $\left[e \cdot \AA^{-3}\right]$ & 0.393 and -0.548 \\
\hline
\end{tabular}




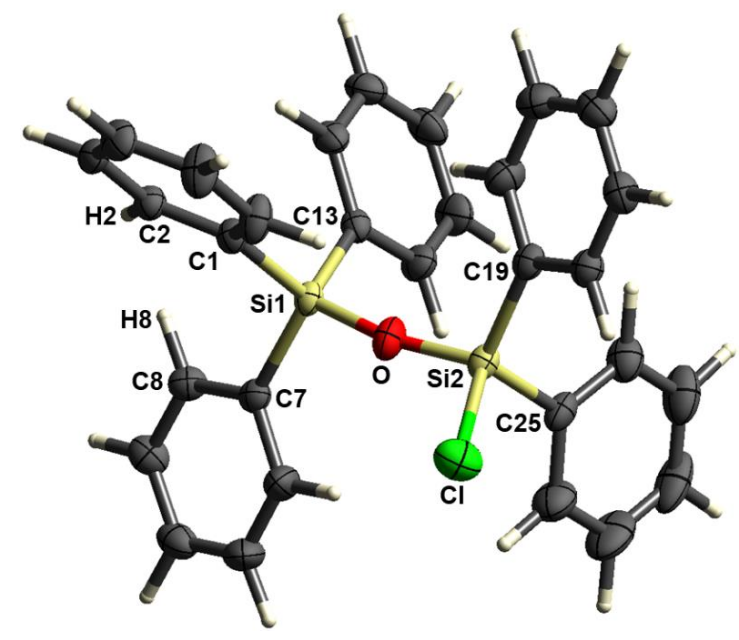

Figure 1. Molecular structure of chloropentaphenyldisiloxane (2) (displacement ellipsoids set at the $50 \%$ probability level). Selected bond lengths $(\AA)$ and angles $\left({ }^{\circ}\right)$ : Si1-C1 1.8649(12), Si1-C7 1.8636(13), Si1-C13 1.8595(13), Si2-C19 1.8543(14), Si2-C25 1.8516(13), Si2-Cl 2.0700(5), Si1-O 1.6305(10), Si2O 1.6012(10), Si1-O-Si2 165.08(8), O-Si2-C19 109.26(6), O-Si2-C25 111.83(6), O-Si2-Cl 105.62(4). Shortest intramolecular $\mathrm{H} \cdots \mathrm{H}$ contact: $\mathrm{H} 2 \cdots \mathrm{H} 82.423 \AA$ A.

a)

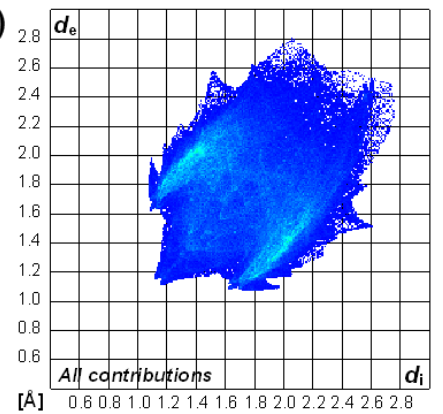

b)

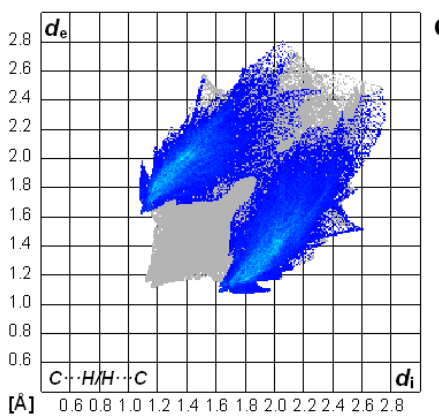

c)

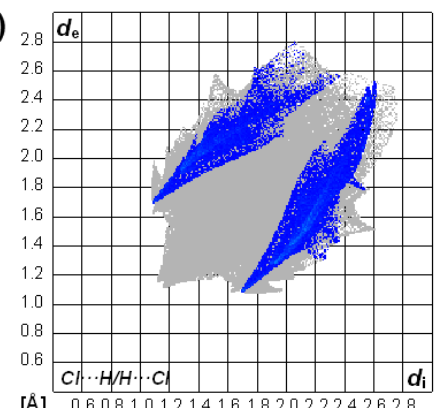

Figure 2. 2D fingerprint plots of chloropentaphenyldisiloxane (2) showing (a) all contributions of intermolecular contacts, (b) $\mathrm{C} \cdots \mathrm{H} / \mathrm{H} \cdots \mathrm{C}(37.9 \%)$, and (c) $\mathrm{Cl} \cdots \mathrm{H} / \mathrm{H} \cdots \mathrm{Cl}(8.9 \%)$ contacts.

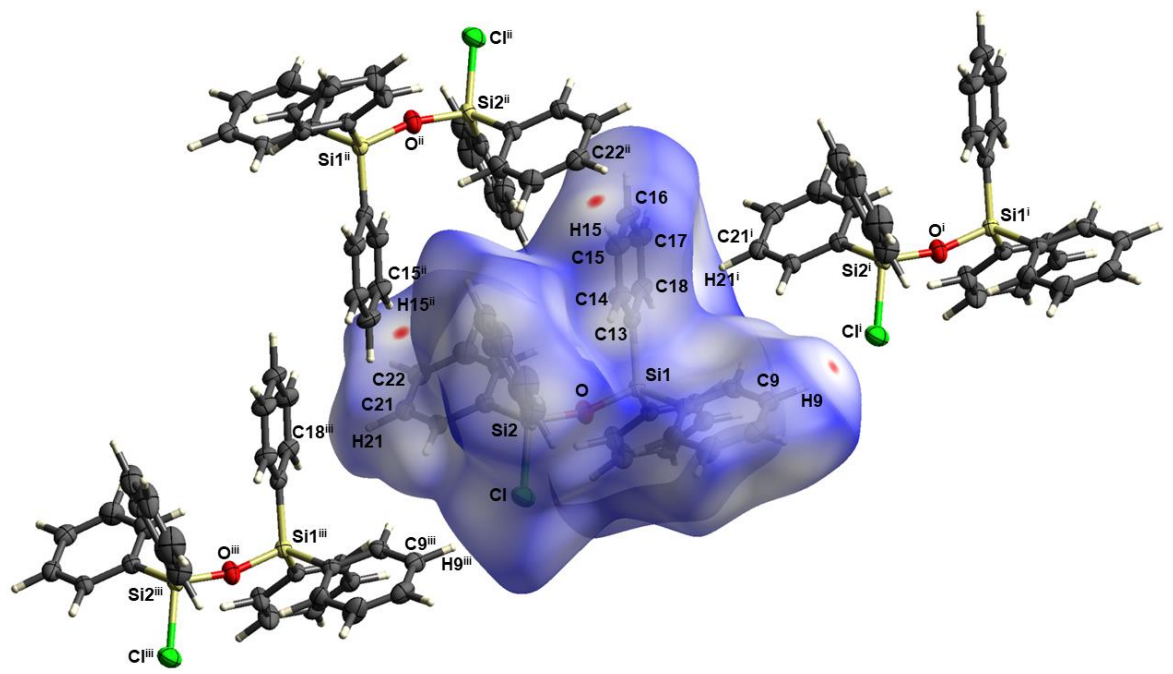

Figure 3. Hirshfeld surface analysis of chloropentaphenyldisiloxane (2) highlighting $\mathrm{C}-\mathrm{H} \cdots \mathrm{Cl}$ and $\mathrm{C}-\mathrm{H} \cdots \pi$ hydrogen bonds (displacement ellipsoids set at the $50 \%$ probability level). Distances $(\AA)$ and angle $\left({ }^{\circ}\right)$ of the C9-H9 $\cdots \mathrm{Cl}$ contact: C9-H9 $0.917, \mathrm{H} 9 \cdots \mathrm{Cl} 2.913, \mathrm{C} 9 \cdots \mathrm{Cl} 3.669, \mathrm{C} 9-\mathrm{H} 9 \cdots \mathrm{Cl} 140.61$. Distances $(\AA)$ and angle $\left(^{\circ}\right)$ of the C15-H15 ․ C22 contact: C15-H15

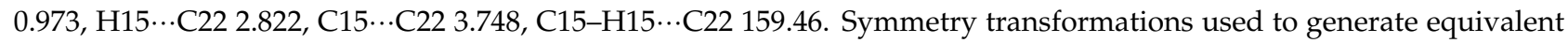
atoms: (i) $-1+\mathrm{x}, \mathrm{y}, \mathrm{z}$; (ii) $1-\mathrm{x}, 1-\mathrm{y}, 1-\mathrm{z}$; (iii) $1+\mathrm{x}, \mathrm{y}, \mathrm{z}$. 


\section{Results and Discussion}

According to a synthetic protocol recently published by us [15], chloropentaphenyldisiloxane (2) was easily obtained in $61 \%$ isolated yield for the first time after reacting dichlorodiphenylsilane (1) with lithium triphenylsiloxide (Scheme 1). The use of metallated siloxide reagents for the stepwise and controlled building of organopolysiloxane polymers was impressively shown by Muzavarov and Rebrov [49]. Recrystallization from hot toluene afforded single-crystals of disiloxane 2 suitable for single-crystal X-ray diffraction analysis (Table 1, Figure 1, see also Supplementary Materials). The asymmetric unit of the monoclinic crystal system, space group $P 2_{1} / n$, contains one molecule of compound 2 . The intramolecular bond parameters of the $\mathrm{Si}-\mathrm{O}-\mathrm{Si}$ backbone show a significantly shortened $\mathrm{Si2}-\mathrm{O}$ bond [1.6012(10) $\AA$ ], i.e., the bond that contains the silicon atom attached to the chlorine substituent, in comparison to the Si1-O bond [1.6305(10) ̊̊] (Figure 1). It has already been noticed earlier that the $\mathrm{Si}-\mathrm{O}-\mathrm{Si}$ bond angle in chloro-substituted disiloxanes is remarkably larger than in the respective methoxy- and aminodisiloxanes [15]. In compound 2 , the Si1-O-Si2 bond angle of $165.08(8)^{\circ}$ is even larger than in the previously described [15] chlorodisiloxane $\mathrm{MesPSiCl}\left(\mathrm{OSiPh}_{3}\right)$ and, together with the short $\mathrm{Si} 2-\mathrm{O}$ bond, may be indicative for a pronounced negative hyperconjugation of the type $\mathrm{LP}(\mathrm{O}) \rightarrow \sigma^{*}(\mathrm{Si}-\mathrm{R})[50,51]$. However, neither the $\mathrm{Si2}-\mathrm{Cl}$ bond $[2.0700(5) \AA]$ nor the $\mathrm{Si}-\mathrm{C}$ bonds show any appreciable elongation when compared to other aryl-substituted chlorosilanes [52-54]. A thorough analysis of the $\mathrm{Si}-\mathrm{O}-\mathrm{Si}$ bonding parameters is not only important for organosiloxanes, but also in the crystal chemistry of minerals and has contributed significantly to a deeper understanding of mineral properties [55].
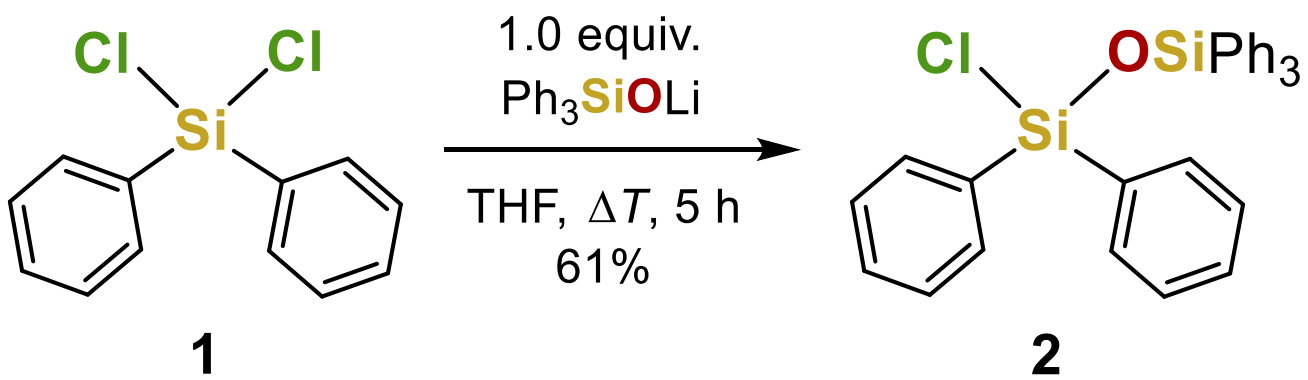

Scheme 1. Synthesis of chloropentaphenyldisiloxane (2).

Figure 2 shows the 2D fingerprint diagrams of intermolecular interactions in the crystal structure of disiloxane 2 , all contributions (plot a) and subdivided into the individual contributions between atoms inside and outside the Hirshfeld surfaces (plots $\mathbf{b}$ and $\mathbf{c}$ ). As expected, isotropic $\mathrm{H} \cdots \mathrm{H}$ contacts $(52.9 \%)$ make the largest percentage contribution to the intermolecular interactions. The point on the Hirshfeld surface where $d_{\mathrm{i}}=d_{\mathrm{e}} \approx 1.2 \AA$ belongs to the shortest intermolecular $\mathrm{H} \cdots \mathrm{H}$ contact, i.e., H5 $\cdots \mathrm{H} 14(2.455 \AA)$, which is not unusually short for $\mathrm{H} \cdots \mathrm{H}$ contacts between phenyl groups $[25,37,38,56]$ and almost as long as the shortest intramolecular $\mathrm{H} \cdots \mathrm{H}$ contact (H2 $\cdots \mathrm{H} 82.423 \AA$ ) (Figures 1 and 2, plot a). Two types of short $\mathrm{C}-\mathrm{H} \cdots \pi$ (i.e., $\mathrm{H} \cdots \mathrm{C}$ ) contacts can be found in the crystal structure of compound 2 (Figure 2, plot b). The closest $\mathrm{H} \cdots \mathrm{C}$ contact amounts to $2.822 \AA\left(d_{\mathrm{i}} \approx\right.$ $1.65 \AA, d_{\mathrm{e}} \approx 1.15 \AA$ ), is represented by the spikes, and contains a $\mathrm{C}-\mathrm{H}$ bond directed towards a single carbon atom (C15-H15 ‥C22) (Figure 3). The other of these shortest $\mathrm{C}-\mathrm{H} \cdots \pi$ contacts, located at $d_{\mathrm{i}} \approx 1.8 \AA$ and $d_{\mathrm{e}} \approx 1.1 \AA$, within the only faintly indicated but typical wing at the lower right of the $\mathrm{C} \cdots \mathrm{H} / \mathrm{H} \cdots \mathrm{C}$ contact plot points almost directly to the center of a phenyl ring and can be identified as the $\mathrm{C} 21-\mathrm{H} 21 \cdots \pi(\mathrm{Ph})$ interaction with the $\pi$-bonded acceptor group containing the carbon atoms C13 to C18 (shortest contact: H21 ‥C18 2.901 A) (Table 2 and Figure 3). 


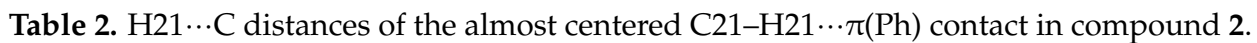

\begin{tabular}{|c|c|}
\hline Contact & Distance (Å) \\
\hline $\mathrm{H} 21 \cdots \mathrm{C} 13$ & 2.997 \\
\hline $\mathrm{H} 21 \cdots \mathrm{C} 14$ & 3.083 \\
\hline $\mathrm{H} 21 \cdots \mathrm{C} 15$ & 3.093 \\
\hline $\mathrm{H} 21 \cdots \mathrm{C} 16$ & 3.001 \\
\hline $\mathrm{H} 21 \cdots \mathrm{C} 17$ & 2.908 \\
\hline $\mathrm{H} 21 \cdots \mathrm{C} 18$ & 2.901 \\
\hline
\end{tabular}

The designation of a $\mathrm{C}-\mathrm{H} \cdots \pi$ contact as a hydrogen bond $[57,58]$ applies at least to the most acidic $\mathrm{C}-\mathrm{H}$ donors such as alkynyl $\mathrm{C} \equiv \mathrm{C}-\mathrm{H}$ groups $[59,60] . \mathrm{C}-\mathrm{H} \cdots \pi(\mathrm{Ph})$ interactions, even with weak $\mathrm{C}\left(\mathrm{sp}^{2}\right)-\mathrm{H}$ or even $\mathrm{C}\left(\mathrm{sp}^{3}\right)-\mathrm{H}$ donors, generally still have important structuredetermining and directing abilities, although they are borderline cases at the weak end of the hydrogen bond classification [26,59]. It was impressively shown by Nishio et al. [61] that $\mathrm{C}-\mathrm{H} \cdots \pi$ interactions can play a crucial role in molecular recognition, for the formation of inclusion compounds, and in controlling specificities in organic reactions. Furthermore, due to their weak but still orienting character, they should also play an important role in the dynamic formation of supramolecular structures of biopolymers during the processes in living cells. Recently, the importance of anisotropic $\mathrm{C}-\mathrm{H} \cdots \pi$ interactions in the crystal structure formation of arylmethoxysilanes has also been pointed out [26].

There are no intermolecular $\mathrm{C}-\mathrm{H} \cdots \mathrm{O}$ contacts to be found, which, on the one hand, can be explained by the difficult steric accessibility of the effectively shielded siloxane oxygen atom as a consequence of the large $\mathrm{Si}-\mathrm{O}-\mathrm{Si}$ angle of $165.08(8)^{\circ}$. On the other hand, this might also have an electronic reason, as recently pointed out by theoretical investigations on the hydrogen bond interaction energy as a function of the $\mathrm{Si}-\mathrm{O}-\mathrm{Si}$ angle [51]. In this picture, the decreased accessibility of oxygen lone electron pairs due to increased negative hyperconjugation may be the reason for the low basicity of the $\mathrm{Si}-\mathrm{O}-\mathrm{Si}$ linkage in compound 2. This could be interesting with regard to a siloxane-functional group cooperation and lead to the design of precisely defined functional units in which intramolecular $\mathrm{Si}-\mathrm{O}-\mathrm{Si}$ specific bond parameters can influence the acceptor capabilities of functional groups or vice versa.

The fingerprint plot for the $\mathrm{Cl} \cdots \mathrm{H} / \mathrm{H} \cdots \mathrm{Cl}$ contacts shows distinct spikes that closely resemble that of typical hydrogen bonding pattern (Figure 2, plot c) [26,37]. In the meanwhile, the existence of $\mathrm{C}-\mathrm{H} \cdots \mathrm{Cl}$ hydrogen bonds has been well documented and evidenced [62-65]. The $\mathrm{H} \cdots \mathrm{Cl}$ contact in disiloxane 2 is represented by the spike where $d_{\mathrm{i}}$ $\approx 1.7 \AA$ and $d_{\mathrm{e}} \approx 1.1 \AA$ (actually found in the crystal structure: $2.913 \AA$ ) and belongs to the $\mathrm{C} 9-\mathrm{H} 9 \cdots \mathrm{Cl}-\mathrm{Si} 2$ hydrogen bond $\left(\mathrm{C} 9 \cdots \mathrm{Cl} 3.669 \AA, \mathrm{C} 9-\mathrm{H} 9 \cdots \mathrm{Cl} 140.61^{\circ}\right)$ (Figure 3). It is in the range of the sum of the van der Waals radii for hydrogen $(1.2 \AA)$ and chlorine $(1.75 \AA$ ) [66] and is quite the same as found for $\mathrm{H} \cdots \mathrm{Cl}$ contacts in chloroform at around $2.95 \AA$ [37]. Since the $\mathrm{H} 9 \cdots \mathrm{Cl}$ distance is also in the typical range for chloro-substituted hydrocarbons [63], we therefore anticipate an essentially anisotropic contribution of the C$\mathrm{H} \cdots \mathrm{Cl}-\mathrm{Si}$ hydrogen bond with a directional influence on the crystal packing. The essential directing structure-forming interactions that were identified from the Hirshfeld surface analysis are also clearly reflected in the crystal packing of disiloxane 2 (Figure A1).

For comparison: In $\mathrm{MesPhSiCl}\left(\mathrm{OSiPh}_{3}\right)$ [15], the $\mathrm{C} \cdots \mathrm{H} / \mathrm{H} \cdots \mathrm{C}$ and $\mathrm{Cl} \cdots \mathrm{H} / \mathrm{H} \cdots \mathrm{Cl}$ contacts with $29.8 \%$ and $6.4 \%$, respectively, contribute less to the intermolecular interactions. Although, the directionality of these contacts seems to be less pronounced in $\mathrm{MesPhSiCl}\left(\mathrm{OSiPh}_{3}\right)$, the mesityl $\mathrm{CH}_{3}$ groups can also participate in intermolecular interactions.

\section{Conclusions}

Monofunctional disiloxanes are scarce, but helpful model systems in order to provide information on substituent effects on the $\mathrm{Si}-\mathrm{O}-\mathrm{Si}$ structural motif and on the packing in the molecular crystalline state. The present investigation on intermolecular interactions in the crystal structure of a chlorodisiloxane (2) was carried out using Hirshfeld surface analysis 
and 2D fingerprint plots. Two major types of anisotropic short $\mathrm{C}-\mathrm{H} \cdots \pi$ contacts and a C $\mathrm{H} \cdots \mathrm{Cl}-\mathrm{Si}$ hydrogen bond-like interaction were identified to have the strongest directional influence on the packing within the molecular crystal. Although the siloxane unit does not appear to have a pronounced effect on the chlorine substituent in this molecule, it seems worthwhile to address the influence of the siloxane motif on the acceptor capabilities of functional groups directly connected to the $\mathrm{Si}-\mathrm{O}-\mathrm{Si}$ unit in future investigations. The information on intermolecular interactions provided herein may be of particular interest with regard to the design of supramolecular functional polysiloxane architectures.

Supplementary Materials: CCDC-2068445 (compound 2) contains the supplementary crystallographic data for this paper. These data can be obtained free of charge from the Cambridge Crystallographic Data Centre, CCDC, 12 Union Road, Cambridge CB21EZ, UK (Fax: + 44-1223-336-033; E-mail: deposit@ccdc.cam.ac.uk; https://www.ccdc.cam.ac.uk/structures/).

Author Contributions: Conceptualization, J.O.B.; methodology, J.O.B. and T.G.; validation, J.O.B. and T.G.; formal analysis, J.O.B.; investigation, J.O.B. and T.G.; resources, J.O.B.; data curation, J.O.B. and T.G.; writing—original draft preparation, J.O.B.; writing—review and editing, J.O.B. and T.G.; visualization, J.O.B.; supervision, J.O.B.; project administration, J.O.B.; funding acquisition, J.O.B. All authors have read and agreed to the published version of the manuscript.

Funding: This research was funded by the University of Regensburg, the Elite Network of Bavaria (ENB), and the Bavarian State Ministry of Science and the Arts (StMWK), grant number N-LWNW-2016-366.

Data Availability Statement: The data presented in this study are available in Supplementary Materials.

Acknowledgments: The authors would like to thank Manfred Scheer and Jörg Heilmann for continuous support and providing laboratory facilities.

Conflicts of Interest: The authors declare no conflict of interest.

Appendix A

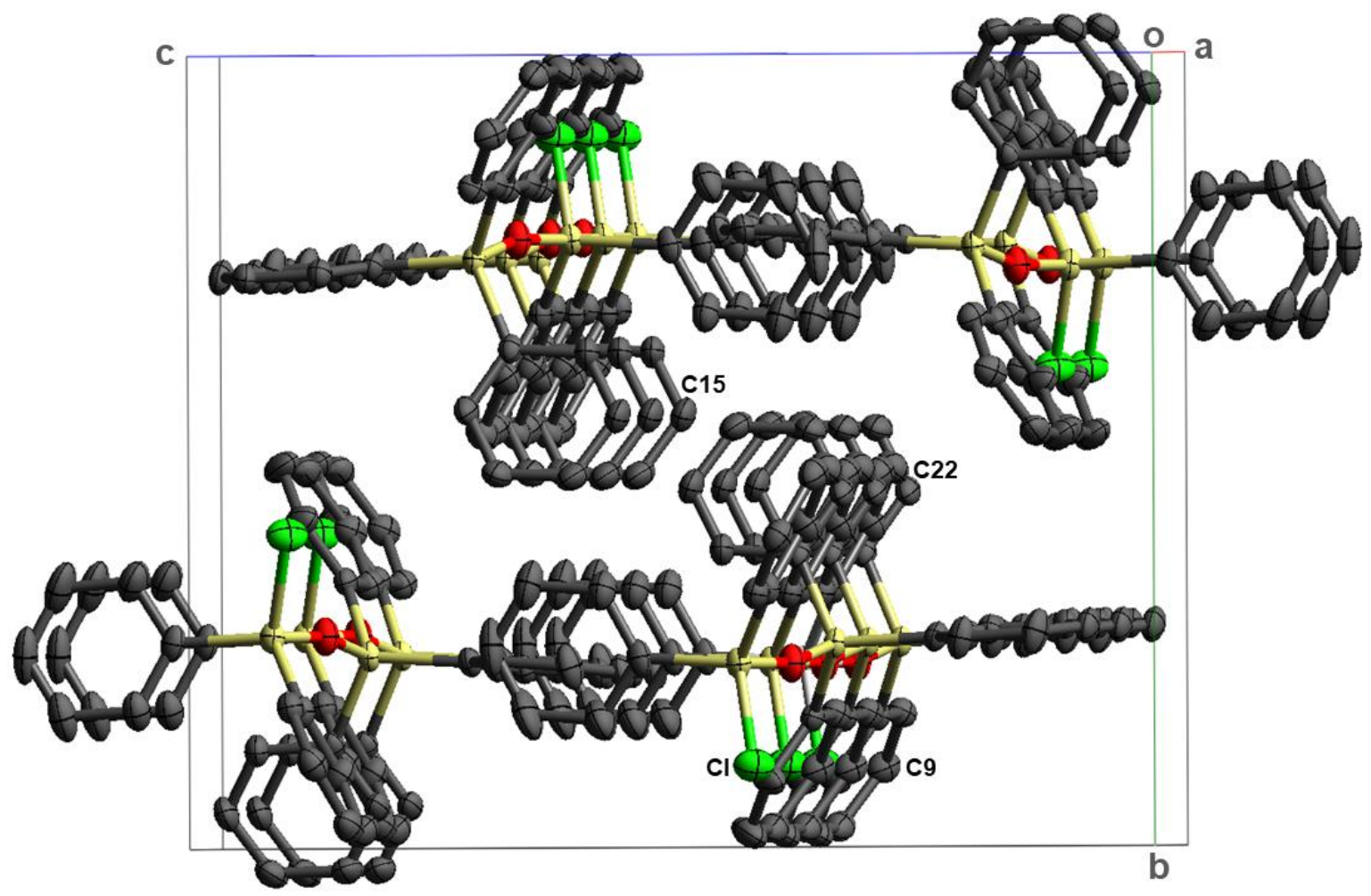

Figure A1. Crystal packing of chloropentaphenyldisiloxane (2) along the a axis. Hydrogen atoms are omitted for clarity. 


\section{References}

1. Liebau, F. Structural Chemistry of Silicates: Structure, Bonding, and Classification; Springer: Berlin/Heidelberg, Germany, 1985.

2. Swaddle, T.W.; Salerno, J.; Tregloan, P.A. Aqueous aluminates, silicates, and aluminosilicates. Chem. Soc. Rev. 1994, $23,319-325$. [CrossRef]

3. Perry, C.C.; Keeling-Tucker, T. Biosilicification: The role of the organic matrix in structure control. J. Biol. Inorg. Chem. 2000, 5, 537-550. [CrossRef]

4. Ganachaud, S.; Boileau, S.; Boury, B. Silicon Based Polymers: Advances in Synthesis and Supramolecular Organization; Springer: Berlin/Heidelberg, Germany, 2008.

5. Schubert, U.; Hüsing, N. Synthesis of Inorganic Materials, 4th ed.; Wiley-VCH: Weinheim, Germany, 2019.

6. Höppe, H.A.; Stadler, F.; Oeckler, O.; Schnick, W. Ca[Si $\left.\mathrm{O}_{2} \mathrm{~N}_{2}\right]$-A Novel Layer Silicate. Angew. Chem. Int. Ed. 2004, 43, 5540-5542. [CrossRef] [PubMed]

7. Däschlein, C.; Bauer, J.O.; Strohmann, C. From the Selective Cleavage of the Si-O-Si Bond in Disiloxanes to Zwitterionic, Water-Stable Zinc Silanolates. Angew. Chem. Int. Ed. 2009, 48, 8074-8077. [CrossRef]

8. Spirk, S.; Nieger, M.; Belaj, F.; Pietschnig, R. Formation and hydrogen bonding of a novel POSS-trisilanol. Dalton Trans. 2008, 163-167. [CrossRef]

9. Hurkes, N.; Bruhn, C.; Belaj, F.; Pietschnig, R. Silanetriols as Powerful Starting Materials for Selective Condensation to Bulky POSS Cages. Organometallics 2014, 33, 7299-7306. [CrossRef]

10. Čas, D.; Hurkes, N.; Spirk, S.; Belaj, F.; Bruhn, C.; Rechberger, G.N.; Pietschnig, R. Dimer formation upon deprotonation: Synthesis and structure of a $m$-terphenyl substituted $(R, S)$-dilithium disiloxanolate disilanol. Dalton Trans. 2015, 44, 12818-12823. [CrossRef]

11. Oguri, N.; Egawa, Y.; Takeda, N.; Unno, M. Janus-Cube Octasilsesquioxane: Facile Synthesis and Structure Elucidation. Angew. Chem. Int. Ed. 2016, 55, 9336-9339. [CrossRef] [PubMed]

12. Lokare, K.S.; Frank, N.; Braun-Cula, B.; Goikoetxea, I.; Sauer, J.; Limberg, C. Trapping Aluminum Hydroxide Clusters with Trisilanols during Speciation in Aluminum(III)-Water Systems: Reproducible, Large Scale Access to Molecular Aluminate Models. Angew. Chem. Int. Ed. 2016, 55, 12325-12329. [CrossRef]

13. Bauer, J.O.; Strohmann, C. Synthesis and molecular structure of a zwitterionic ZnI 2 silanolate. Inorg. Chim. Acta 2018, 469, 133-135. [CrossRef]

14. Lokare, K.S.; Braun-Cula, B.; Limberg, C.; Jorewitz, M.; Kelly, J.T.; Asmis, K.R.; Leach, S.; Baldauf, C.; Goikoetxea, I.; Sauer, J. Structure and Reactivity of $\mathrm{Al}-\mathrm{O}(\mathrm{H})-\mathrm{Al}$ Moieties in Siloxide Frameworks: Solution and Gas-Phase Model Studies. Angew. Chem. Int. Ed. 2019, 58, 902-906. [CrossRef]

15. Espinosa-Jalapa, N.A.; Bauer, J.O. Controlled Synthesis and Molecular Structures of Methoxy-, Amino-, and Chloro-Functionalized Disiloxane Building Blocks. Z. Anorg. Allg. Chem. 2020, 646, 828-834. [CrossRef]

16. Weitkamp, R.F.; Neumann, B.; Stammler, H.; Hoge, B. Synthesis and Reactivity of the First Isolated Hydrogen-Bridged SilanolSilanolate Anions. Angew. Chem. Int. Ed. 2020, 59, 5494-5499. [CrossRef] [PubMed]

17. Weitkamp, R.F.; Neumann, B.; Stammler, H.-G.; Hoge, B. The Influence of Weakly Coordinating Cations on the $\mathrm{O}^{-} \mathrm{H}^{-\cdots \mathrm{O}^{-}}$ Hydrogen Bond of Silanol-Silanolate Anions. Chem. Eur. J. 2021, 27, 915-920. [CrossRef] [PubMed]

18. Tacke, R. Milestones in the Biochemistry of Silicon: From Basic Research to Biotechnological Applications. Angezw. Chem. Int. Ed. 1999, 38, 3015-3018. [CrossRef]

19. Voinescu, A.E.; Kellermeier, M.; Bartel, B.; Carnerup, A.M.; Larsson, A.-K.; Touraud, D.; Kunz, W.; Kienle, L.; Pfitzner, A.; Hyde, S.T. Inorganic Self-Organized Silica Aragonite Biomorphic Composites. Cryst. Growth Des. 2008, 8, 1515-1521. [CrossRef]

20. Volkmer, D.; Tugulu, S.; Fricke, M.; Nielsen, T. Morphosynthesis of Star-Shaped Titania-Silica Shells. Angew. Chem. Int. Ed. 2003, 42, 58-61. [CrossRef]

21. Desiraju, G.R. Supramolecular Synthons in Crystal Engineering-A New Organic Synthesis. Angew. Chem. Int. Ed. Engl. 1995, 34, 2311-2327. [CrossRef]

22. Desiraju, G.R. Hydrogen Bridges in Crystal Engineering: Interactions without Borders. Acc. Chem. Res. 2002, 35, 565-573. [CrossRef]

23. Thompson, D.B.; Brook, M.A. Rapid Assembly of Complex 3D Siloxane Architectures. J. Am. Chem. Soc. 2008, 130, 32-33. [CrossRef]

24. Bauer, J.O. The crystal structure of the triclinic polymorph of hexameric (trimethylsilyl)methyllithium, $\mathrm{C}_{24} \mathrm{H}_{66} \mathrm{Li}_{6} \mathrm{Si}_{6}$. Z. Kristallogr. NCS 2020, 235, 353-356. [CrossRef]

25. Bauer, J.O. The crystal structure of the first ether solvate of hexaphenyldistannane $\left[\left(\mathrm{Ph}_{3} \mathrm{Sn}\right)_{2} \cdot 2 \mathrm{THF}\right]$. Main Group Met. Chem. 2020, 43, 1-6. [CrossRef]

26. Bauer, J.O. Crystal Structure and Hirshfeld Surface Analysis of Trimethoxy(1-naphthyl)silane-Intermolecular Interactions in a One-Component Single-Crystalline Trimethoxysilane. Z. Anorg. Allg. Chem. 2021, 647, 1053-1057. [CrossRef]

27. Pietschnig, R.; Merz, K. Selective Formation of Functionalized Disiloxanes from Terphenylfluorosilanes. Organometallics 2004, 23, 1373-1377. [CrossRef]

28. Wojnowski, W.; Becker, B.; Peters, K.; Peters, E.-M.; von Schnering, H.G. Beiträge zur Chemie der Silicium-Schwefel-Verbindungen. 53. Die Struktur des 1,3-Dimethyl-1,1,3,3-Tetraphenyldisilthians. Z. Anorg. Allg. Chem. 1988, 563, 48-52. [CrossRef]

29. Coelho, A.C.; Amarante, T.R.; Klinowski, J.; Gonçalves, I.S.; Almeida Paz, F.A. 1-Hydroxy-1,1,3,3,3-pentaphenyldisiloxane, $\left[\mathrm{Si}_{2} \mathrm{O}(\mathrm{OH})(\mathrm{Ph})_{5}\right]$, at $100 \mathrm{~K}$. Acta Crystallogr. Sect. E 2008, 64, o237-o238. [CrossRef] [PubMed] 
30. Amarante, T.R.; Coelho, A.C.; Klinowski, J.; Gonçalves, I.S.; Almeida Paz, F.A. 1-Hydroxy-1,1,3,3,3-pentaphenyldisiloxane, $\left[\mathrm{Si}_{2} \mathrm{O}(\mathrm{OH})(\mathrm{Ph})_{5}\right]$, at $150 \mathrm{~K}$. Acta Crystallogr. Sect. E 2008, 64, o239. [CrossRef] [PubMed]

31. Bauer, J.O.; Strohmann, C. One-step conversion of methoxysilanes to aminosilanes: A convenient synthetic strategy to $N, O-$ functionalised organosilanes. Chem. Commun. 2012, 48, 7212-7214. [CrossRef]

32. Bauer, J.O.; Strohmann, C. Stereoselective Synthesis of Silicon-Stereogenic Aminomethoxysilanes: Easy Access to Highly Enantiomerically Enriched Siloxanes. Angew. Chem. Int. Ed. 2013, 53, 720-724. [CrossRef]

33. Woińska, M.; Grabowsky, S.; Dominiak, P.M.; Woźniak, K.; Jayatilaka, D. Hydrogen atoms can be located accurately and precisely by x-ray crystallography. Sci. Adv. 2016, 2, e1600192. [CrossRef]

34. Wakabayashi, R.; Sugiura, Y.; Shibue, T.; Kuroda, K. Practical Conversion of Chlorosilanes into Alkoxysilanes without Generating HCl. Angew. Chem. Int. Ed. 2011, 50, 10708-10711. [CrossRef]

35. Deschner, T.; Liang, Y.; Anwander, R. Silylation Efficiency of Chorosilanes, Alkoxysilanes, and Monosilazanes on Periodic Mesoporous Silica. J. Phys. Chem. C 2010, 114, 22603-22609. [CrossRef]

36. Spackman, M.A.; Jayatilaka, D. Hirshfeld surface analysis. CrystEngComm 2009, 11, 19-32. [CrossRef]

37. Spackman, M.A.; McKinnon, J.J. Fingerprinting intermolecular interactions in molecular crystals. CrystEngComm 2002, 4, 378-392. [CrossRef]

38. Bauer, J.O.; Strohmann, C. tert-Butoxytriphenylsilane. Acta Crystallogr. Sect. E 2010, 66, o461-o462. [CrossRef]

39. Bauer, J.O.; Strohmann, C. Hydrogen bonding principles in inclusion compounds of triphenylsilanol and pyrrolidine: Synthesis and structural features of $\left[\left(\mathrm{Ph}_{3} \mathrm{SiOH}\right)_{4} \cdot \mathrm{HN}\left(\mathrm{CH}_{2}\right)_{4}\right]$ and $\left[\mathrm{Ph}_{3} \mathrm{SiOH} \cdot \mathrm{HN}\left(\mathrm{CH}_{2}\right)_{4} \cdot \mathrm{CH}_{3} \mathrm{CO}_{2} \mathrm{H}\right]$. J. Organomet. Chem. 2015, 797, 52-56. [CrossRef]

40. Lokare, K.S.; Wittwer, P.; Braun-Cula, B.; Frank, N.; Hoof, S.; Braun, T.; Limberg, C. Mimicking Base Interaction with Acidic Sites [Si-O $(H)-\mathrm{Al}$ ] of Zeolites in Molecular Models. Z. Anorg. Allg. Chem. 2017, 643, 1581-1588. [CrossRef]

41. Rigaku Oxford Diffraction. Crys AlisPro Software System; Rigaku Corporation: Oxford, UK, 2018.

42. Sheldrick, G.M. SHELXT-Integrated space-group and crystal-structure determination. Acta Crystallogr. Sect. A 2015, 71, 3-8. [CrossRef]

43. Sheldrick, G.M. A short history of SHELX. Acta Crystallogr. Sect. A 2008, 64, 112-122. [CrossRef] [PubMed]

44. Sheldrick, G.M. Crystal structure refinement with SHELXL. Acta Crystallogr. Sect. C 2015, 71, 3-8. [CrossRef]

45. Sheldrick, G.M. SHELXL-2018; Universität Göttingen: Göttingen, Germany, 2018.

46. Dolomanov, O.V.; Bourhis, L.J.; Gildea, R.J.; Howard, J.A.K.; Puschmann, H. OLEX2: A complete structure solution, refinement and analysis program. J. Appl. Crystallogr. 2009, 42, 339-341. [CrossRef]

47. Farrugia, L.J. WinGX and ORTEP for Windows: An update. J. Appl. Crystallogr. 2012, 45, 849-854. [CrossRef]

48. Turner, M.J.; McKinnon, J.J.; Wolff, S.K.; Grimwood, D.J.; Spackman, P.R.; Jayatilaka, D.; Spackman, M.A. CrystalExplorer17; University of Western Australia: Perth, Australia, 2017.

49. Muzafarov, A.M.; Rebrov, E.A. From the Discovery of Sodiumoxyorganoalkoxysilanes to the Organosilicon Dendrimers and Back. J. Polym. Sci. Part A: Polym. Chem. 2008, 46, 4935-4948. [CrossRef]

50. Weinhold, F.; West, R. Hyperconjugative Interactions in Permethylated Siloxanes and Ethers: The Nature of the SiO Bond. J. Am. Chem. Soc. 2013, 135, 5762-5767. [CrossRef]

51. Fugel, M.; Hesse, M.F.; Pal, R.; Beckmann, J.; Jayatilaka, D.; Turner, M.J.; Karton, A.; Bultinck, P.; Chandler, G.S.; Grabowsky, S. Covalency and Ionicity Do Not Oppose Each Other-Relationship Between Si-O Bond Character and Basicity of Siloxanes. Chem. Eur. J. 2018, 24, 15275-15286. [CrossRef] [PubMed]

52. Liew, S.K.; Al-Rafia, S.M.I.; Goettel, J.T.; Lummis, P.A.; McDonald, S.M.; Miedema, L.J.; Ferguson, M.J.; McDonald, R.; Rivard, E. Expanding the Steric Coverage Offered by Bis(amidosilyl) Chelates: Isolation of Low-Coordinate $\mathrm{N}$-Heterocyclic Germylene Complexes. Inorg. Chem. 2012, 51, 5471-5480. [CrossRef] [PubMed]

53. Reuter, K.; Maas, R.G.M.; Reuter, A.; Kilgenstein, F.; Asfaha, Y.; von Hänisch, C. Synthesis of heteroatomic bridged paracyclophanes. Dalton Trans. 2017, 46, 4530-4541. [CrossRef]

54. Marin-Luna, M.; Pölloth, B.; Zott, F.; Zipse, H. Size-dependent rate acceleration in the silylation of secondary alcohols: The bigger the faster. Chem. Sci. 2018, 9, 6509-6515. [CrossRef]

55. Gibbs, G.V.; Downs, R.T.; Cox, D.F.; Ross, N.L.; Prewitt, C.T.; Rosso, K.M.; Lippmann, T.; Kirfel, A. Bonded interactions and the crystal chemistry of minerals: A review. Z. Kristallogr. 2008, 223, 1-40. [CrossRef]

56. Brendler, E.; Heine, T.; Seichter, W.; Wagler, J.; Witter, R. ${ }^{29}$ Si NMR Shielding Tensors in Triphenylsilanes- ${ }^{29}$ Si Solid State NMR Experiments and DFT-IGLO Calculations. Z. Anorg. Allg. Chem. 2012, 638, 935-944. [CrossRef]

57. Arunan, E.; Desiraju, G.R.; Klein, R.A.; Sadlej, J.; Scheiner, S.; Alkorta, I.; Clary, D.C.; Crabtree, R.H.; Dannenberg, J.J.; Hobza, P.; et al. Defining the hydrogen bond: An account (IUPAC Technical Report). Pure Appl. Chem. 2011, 83, $1619-1636$. [CrossRef]

58. Arunan, E.; Desiraju, G.R.; Klein, R.A.; Sadlej, J.; Scheiner, S.; Alkorta, I.; Clary, D.C.; Crabtree, R.H.; Dannenberg, J.J.; Hobza, P.; et al. Definition of the hydrogen bond (IUPAC Recommendations 2011). Pure Appl. Chem. 2011, 83, $1637-1641$. [CrossRef]

59. Steiner, T. The Hydrogen Bond in the Solid State. Angew. Chem. Int. Ed. 2002, 41, 48-76. [CrossRef] 
60. Steiner, T.; Starikov, E.B.; Amado, A.M.; Teixeira-Dias, J.J.C. Weak hydrogen bonding. Part 2. The hydrogen bonding nature of short $\mathrm{C}-\mathrm{H} \cdots \pi$ contacts: Crystallographic, spectroscopic and quantum mechanical studies of some terminal alkynes. J. Chem. Soc. Perkin Trans. 2 1995, 1321-1326. [CrossRef]

61. Nishio, M.; Umezawa, Y.; Hirota, M.; Takeuchi, Y. The CH/ $\pi$ Interaction: Significance in Molecular Recognition. Tetrahedron 1995, 51, 8665-8701. [CrossRef]

62. Taylor, R.; Kennard, O. Crystallographic Evidence for the Existence of C-H $\cdots \mathrm{O}, \mathrm{C}-\mathrm{H} \cdots \mathrm{N}$, and C-H $\cdots \mathrm{Cl}$ Hydrogen Bonds. J. Am. Chem. Soc. 1982, 104, 5063-5070. [CrossRef]

63. Desiraju, G.R.; Parthasarathy, R. The Nature of Halogen $\cdots$ Halogen Interactions: Are Short Halogen Contacts Due to Specific Attractive Forces or Due to Close Packing of Nonspherical Atoms? J. Am. Chem. Soc. 1989, 111, 8725-8726. [CrossRef]

64. Aakeröy, C.B.; Evans, T.A.; Seddon, K.R.; Pálinkó, I. The C-H..Cl hydrogen bond: Does it exist? New J. Chem. 1999, $23,145-152$. [CrossRef]

65. Liu, M.; Yin, C.; Chen, P.; Zhang, M.; Parkin, S.; Zhou, P.; Li, T.; Yu, F.; Long, S. ${ }^{\text {sp2 }}{ }^{2} \mathrm{CH}$ - . Cl hydrogen bond in the conformational polymorphism of 4-chloro-phenylanthranilic acid. CrystEngComm 2017, 19, 4345-4354. [CrossRef]

66. Bondi, A. van der Waals Volumes and Radii. J. Phys. Chem. 1964, 68, 441-451. [CrossRef] 